\title{
Deep Nephron Function after Release of Acute Unilateral Ureteral Obstruction in the Young Rat
}

\author{
John Buerkert, Daniel Martin, Mary Head, Jagadish Prasad, and \\ SAUlo KLAHR, Renal Physiology Laboratory, John Cochran Veterans \\ Administration Hospital, St. Louis, Missouri 63106, and Renal Division, \\ Department of Medicine, Washington University School of Medicine, \\ St. Louis, Missouri 63110
}

A B S T R A C T The effects of acute unilateral ureteral obstruction (UUO) of $18 \mathrm{~h}$ duration on deep nephron function was evaluated in 14 weanling rats with the technique of micropuncture. After release of UUO, $3.40 \pm 0.66 \%$ (SE) of the filtered water remained at the tip of the collecting duct nearly fivefold greater than in controls $(0.75 \pm 0.10 \%)$. Similar differences were seen in fractional sodium that remained at this site. The ratio of tubular fluid osmolality to that of plasma was also reduced in the UUO group ( $1.53 \pm 0.06$ vs. $4.60 \pm 0.26$ in controls, $P<0.001$ ).

Single nephron glomerular filtration rate of cortical and deep nephrons was significantly less $(P<0.001)$ after release of UUO. Although the percentage of filtering nephrons was significantly reduced in both nephron populations, the decline in glomerular filtration rate was greater in cortical than in juxtamedullary nephrons (cortical:juxtamedullary nephrons $=27.6 \pm 4.5 \%$ vs. $53.3 \pm 5.2 \%$ in controls, $P<0.005$ ) which suggests that single nephron glomerular filtration rate is redistributed to deep nephrons after release of UUO.

In contrast to cortical nephrons, the amount of tubular fluid which remains near the bend of the loop of Henle of deep nephrons was greater after release of UUO. This appeared to be the result of a decrease in the reabsorption of both water (tubular fluid:plasma inulin $=2.41 \pm 0.16$ vs. $7.94 \pm 0.69$ in controls, $P<0.001$ ) and sodium $(52.3 \pm 4 \%$ vs. $40.7 \pm 2.9 \%$ of the filtered sodium in controls, $P<0.02$ ). It is suggested that this altered

Portions of this work have been presented in abstract form: Buerkert, J., D. Martin, M. Head, J. Prasad, and S. Klahr. 1977. Collecting duct and juxtamedullary nephron function after release of acute unilateral ureteral obstruction. Clin. Res. 25: 593A. (Abstr.)

Dr. John Buerkert is a Research Associate of the Veterans Administration.

Received for publication 12 January 1978 and in revised form 23 August 1978. reabsorption occurs along both the proximal tubule and descending limb of the loop of Henle of juxtamedullary nephrons.

Inner medullary plasma flow (IMPF), as measured with the [125I]albumin-accumulation technique, was significantly depressed before release of UUO, but exceeded control values 90 min postrelease. Such changes imply that the filtration fraction of deep nephrons is decreased and that physical factors in the proximal tubular reabsorption of sodium have been altered. When papillary solute content was measured before release of UUO it was low $(428 \pm 23 \mathrm{vs} .1,205 \pm 106 \mathrm{mosmol} / \mathrm{kg}$ in controls, $P<0.001$ ) which indicates that the decline in papillary osmolality is not a consequence of the increased IMPF seen after ureteral release, but rather precedes it. In fact, the decline in papillary osmolality may contribute to the increase in IMPF after release of UUO and to the decreased reabsorption of fluid along the descending limb of the loop of Henle.

\section{INTRODUCTION}

Many of the pathophysiologic events which occur after release of complete ureteral obstruction differ depending upon whether one or both kidneys are involved. In man (1-3) and experimental animals (4-7), a marked diuresis and natriuresis usually occurs after release of bilateral ureteral obstruction (BUO). ${ }^{1}$ Micropuncture studies have shown that, in rats, this "post-obstructive diuresis" is associated with a decrease in the reabsorp-

\footnotetext{
${ }^{1}$ Abbreviations used in this paper: BUO, bilateral ureteral obstruction; CCK, contralateral control kidney; DLH, descending limb of loop of Henle; GFR, glomerular filtration rate; IMPF, inner medullary plasma flow; JM, juxtamedullary; KW, kidney weight; LUO, left ureteral obstruction; RUO, right ureteral obstruction; SNGFR, single nephron glomerular filtration rate; TF/P In, tubular fluid to plasma inulin ratio; UUO, unilateral ureteral obstruction; $V_{t f}$, timed tubular flow rates.
} 
tion of fluid along proximal $(4,5)$ and distal $(4,6)$ tubules of cortical nephrons and to the bend of the loop of Henle of deep nephrons (8). On the other hand, a postobstructive diuresis does not occur after release of unilateral ureteral obstruction (UUO). In fact, the reabsorption of tubular fluid along the accessible length of the cortical nephron is actually increased $(4,9)$. The reinfusion studies of Harris and Yarger (10) and the crosscirculation studies of Wilson and Honrath (11) suggest that the development of a postobstructive diuresis after release of BUO may relate to suppression of the renal tubular reabsorption of sodium and water by substances that accumulated in the blood during the period of anuria. These studies, in conjunction with the micropuncture findings after release of UUO, suggest that the intrinsic reabsorptive capacities of cortical nephrons are not directly affected by ureteral obstruction of short duration.

After release of UUO, despite increased fractional reabsorption of fluid in cortical nephrons, sodium excretion and urine flow are the same as, or sometimes slightly increased, when compared with the contralateral kidney $(4,9)$. Because there is a significant fall in whole kidney and cortical nephron glomerular filtration rates after release of $\mathrm{UUO}(4,9,12)$, it seems likely that the increased fractional excretion of salt and water is a result of decreased fluid reabsorption along the collecting duct or in deep nephrons. Indeed, recent micropuncture studies have shown that the fraction of the filtered load of water which remains at end distal tubular sites ( $90 \%$ length) of surface nephrons was not different from that found in the final urine (4). Furthermore, it has been shown in experimental animals $(9,13,14)$ and in man (15), that after release of UUO, the ability to reabsorb free water is impaired, and maximum urine osmolalities are markedly diminished in the experimental kidney when compared to controls (9).

The role of deep nephrons in these changes has not been adequately studied. With a modification of Hanssen's technique, Harris and Yarger (9) found that after release of UUO only $12 \%$ of deep nephrons were functioning as judged by the presence or absence of Prussian blue in the tubules of dissected nephrons. Such data suggest that deep nephrons are more adversely affected by acute UUO. No information is available concerning alterations in the reabsorption of salt and water by juxtamedullary (JM) nephrons under these conditions.

The present experiments were performed in an attempt to determine whether or not differences in function existed between deep and surface nephrons after release of UUO. We found that after release of acute UUO, single nephron glomerular filtration rate (SNGFR) of deep nephrons decreased, but not to the same extent as that seen in cortical nephrons. Furthermore, the reabsorption of sodium and water in deep nephrons, be- fore the bend of the loop of Henle, was markedly reduced. By contrast, as mentioned above, fluid reabsorption was actually increased in surface nephrons. This model therefore provides evidence that marked differences in function between surface and deep nephrons occur in at least one pathophysiological state.

\section{METHODS}

Approximately $18 \mathrm{~h}$ before study, 117 male Sprague-Dawley rats weighing between 35 and $60 \mathrm{~g}$ were anesthetized lightly with ether, and both ureters were exposed through a midline abdominal incision. In one group (controls), the ureters were visualized but not touched. In another group (UUO), either the right or left ureter was ligated with 4-0 silk at a point approximately one-third of the distance from the bladder to the renal pelvis. All rats were fed a standard rat chow (Ralston Purina Co., St. Louis, Mo.) until the time of the initial surgical procedure. Thereafter, all rats were deprived of food and water.

On the day of the study, the rats were anesthetized with Inactin (Promonta, Hamburg, West Germany) given intraperitoneally $(80-100 \mathrm{mg} / \mathrm{kg}$ body wt). Tracheostomy and intubation were then performed and polyethylene catheters were placed in one or both jugular veins and the right femoral artery as previously described (8). The obstruction was relieved by severing the ureter above the ligature. A catheter was then placed in the bladder for collection of urine from the contralateral untouched kidney in both groups. Immediately after relief of obstruction an inulin prime was given, followed by an infusion of normal saline which contained inulin in sufficient amounts to maintain plasma levels between 50 and 100 $\mathrm{mg} / 100 \mathrm{ml}$. In both control and UUO rats, the mean infusion rate was calculated at $65 \mu \mathrm{l} / \mathrm{min}$ per $100 \mathrm{~g}$ body wt.

Micropuncture studies $(n=27)$. Approximately $15-30 \mathrm{~min}$ after the initiation of the infusion of saline and inulin, the left kidney was prepared for micropuncture and the renal papilla exposed as previously described (8). The micropuncture studies were begun 20-30 min later.

Fluid was collected from the terminal collecting duct at a site near the tip of the papilla. In all cases, sampling was done in duplicate. Timed collections were made from one to three loops punctured near the bend of the loop of Henle. The total length of the papilla was determined with an eyepiece micrometer. Either before or after the papillary micropuncture studies were performed, the cortical surface was illuminated, and tubular fluid samples were obtained from random proximal tubules. The method for the collection of fluid from proximal tubules, the loop of Henle, and the collecting duct has been described previously (8).

Blood samples and blood pressure measurements were obtained either at 30-min intervals or immediately after the collection of tubular fluid. Body temperature was determined with a rectal thermometer and maintained between 36.5 and $38^{\circ} \mathrm{C}$. One to three timed urine collections were obtained in preweighed test tubes and the volumes were determined gravimetrically.

Preparation of micropipettes and determination of the volume of tubular fluid samples was done by methods previously described (8). The concentration of inulin was determined by the fluorometric method of Vurek and Pegram (16). Sodium and potassium were measured with a helium glow photometer (American Instrument Co., Travenol Laboratories, Inc., Silver Spring, Md.). The osmolality of tubular fluid was measured by the method of Ramsay and Brown (17). Recovery values for these micromethods in this laboratory have been reported elsewhere (8). 
Tubular fluid to plasma inulin ratios (TF/P In) permitted a calculation of fractional water reabsorption to the site of micropuncture. SNGFR was calculated from the TF/P In and the timed tubular flow rates $\left(V_{t f}\right),\left(S N G F R=T F / P\right.$ In $\left.\times V_{t f}\right)$. The fraction of filtered water remaining in the tubule was calculated as (P/TF In $\times 100)$. The percentage of filtered sodium, potassium, and solute remaining was determined from the general formula: (TF/P X)/(TF/P In) $\times 100$, where $X$ represents the variable. The concentration of nonelectrolyte solutes in urine and tubular fluid was estimated with the following equation: nonelectrolyte solutes $=$ Osm $-1.84(\mathrm{Na}+\mathrm{K})$, where Osm, $\mathrm{Na}$, and $\mathrm{K}$ represent the osmolality and concentration of sodium and potassium, respectively.

Clearance studies $(n=12)$. These studies were designed to measure whole kidney function after release of UUO, and to determine what effects, if any, result from the manipulations involved in preparing the left kidney for micropuncture. In these studies, six rats had a left ureteral ligation (LUO) and six rats had a right ureteral ligation (RUO) $18 \mathrm{~h}$ before study. On the day of the study, the rats were prepared as if for micropuncture except that the ureteral pelvis was not removed. Instead a polyethylene catheter (PE 50) was placed above the ligature. After an equilibration period of $60 \mathrm{~min}$, three timed urine collections were obtained. Blood pressure measurements and blood samples were obtained at the midpoint of each urine collection.

Ferrocyanide infusion studies $(n=10)$. This series of experiments was designed in an attempt to estimate the percentage of filtering nephrons $90 \mathrm{~min}$ after release of UUO. A modification of Hanssen's technique was utilized (18). Briefly, two groups of rats were studied. The first group consisted of five rats studied after $18 \mathrm{~h}$ of LUO but before release (designated zero time). A second group of five rats, which had undergone LUO of a similar duration, was prepared as described previously for the clearance studies. In this group, the percentage of filtering nephrons was estimated $90 \mathrm{~min}$ after release of UUO.

At the designated time, a $10 \%$ sodium ferrocyanide solution was infused intravenously at a rate of $3.8 \mathrm{ml} / \mathrm{min}$. Approximately 20-30 s after the infusion was begun, the left and right renal pedicles were ligated. The kidneys were quickly removed and frozen in a dry ice-acetone mixture and then broken into fragments. These fragments were placed in a solution composed of $95 \mathrm{ml}$ ethanol, $5 \mathrm{ml}$ concentrated $\mathrm{HCl}$, and $50 \mathrm{~g}$ ferric chloride and maintained at $-20^{\circ} \mathrm{C}$ for $18 \mathrm{~h}$. The fragments were then placed in a $20 \% \mathrm{HCl}$ solution and incubated at $39^{\circ} \mathrm{C}$ for $80 \mathrm{~min}$. They were then transferred to a solution of $1 \%$ acetic acid, $100 \mathrm{mg} / 100 \mathrm{ml}$ ferric chloride solution and allowed to stand at room temperature for $24 \mathrm{~h}$. Superficial and JM nephrons were then microdissected and identified as filtering or nonfiltering by the presence of blue granules in the tubular lumen. In all cases, sufficient sized fragments of cortex were obtained so that at least 10 superficial and JM nephrons could be dissected. In all cases, at least five fragments from each kidney were microdissected.

Inner medullary plasma flow studies $(n=54)$. In these studies, inner medullary plasma flow (IMPF) was determined by the ${ }^{125}$ I-tagged albumin-accumulation technique as described by Solez et al. (19). Briefly, the rats were prepared as if for micropuncture with the exception that before release of ureteral obstruction a ligature (4-0 silk) was placed around the renal pedicle of the right and left kidney. At the designated time, an infusion of normal saline which contained [ ${ }^{125} \mathrm{I}$ ]albumin (sp act $15 \mu \mathrm{Ci} / \mathrm{ml}$, Mallinckrodt Inc., St. Louis, Mo.) and a $2.5 \%$ solution of FD \& C no. 3 (Keystone Standard Colors, Milner Chemical Co., Chicago, Ill.) was infused at a rate of $388 \mu \mathrm{l} / \mathrm{min}$. At precisely the time that the dye appeared at the renal pedicle, a blood collection was begun from the femoral artery in 100- $\mu$ l capillary tubes (Drummend Microcaps, Lawshe Instrument Co., Inc., Bethesda, Md.). In all studies, blood was collected at a constant rate $(0.2-0.4 \mathrm{ml} / \mathrm{min})$ as judged visually. 12-30 s after initiation of the blood collection, the ligature was tightened about the right and left renal pedicle. The kidneys were then taken and sectioned longitudinally. The renal papilla was removed, blotted, and weighed. The blood sample was centrifuged, and the plasma was removed and weighed. Plasma and tissue samples were then counted in a gamma well-type counter (Searle, Diagnostics Inc., G. D. Searle \& Co., Des Plaines, Ill.) for $10 \mathrm{~min}$. IMPF was calculated according to the following formula:

$$
\mathrm{IMPF}=\frac{(\mathrm{cpm} / \mathrm{mg} \text { tissue }) \times 100}{(\mathrm{cpm} / \mu \mathrm{l} \text { plasma }) \cdot \mathrm{T}} \cdot 60,
$$

where $\mathrm{T}$ equals the duration of infusion in seconds, after the appearance of the dye at the renal pedicle. Values are expressed as microliters per minute per $100 \mathrm{mg}$ of papillary wet weight.

IMPF measurements were performed $\cong 18 \mathrm{~h}$ after either sham operation or UUO before relief of obstruction, and 90 and $180 \mathrm{~min}$ postrelease. In those studies done after release of obstruction, an infusion of normal saline and inulin was begun as previously described. The renal papilla was exposed and prepared as if for micropuncture. As in the clearance studies, timed urine collections were obtained from the contralateral untouched kidney, and blood samples were obtained at the midpoint of each urine collection.

Solute content of the papilla $(n=14)$. Approximately $18 \mathrm{~h}$ after sham operation or UUO, the concentrations of sodium, potassium, and urea in the cortex and medulla were determined with a modification of the method of Appelboom et al. (20). In these studies, the rats were anesthetized with Inactin, and the kidneys were exposed through a midline abdominal incision. The renal pedicle was ligated immediately, the kidneys were removed and sectioned longitudinally, and the papilla was excised and weighed. At the same time, a section of the cortex was obtained and weighed. To these weighed specimens, $100 \mu \mathrm{l}$ of water was added. The samples were placed in a boiling water bath for $30 \mathrm{~min}$, sealed, and then left to stand at $4^{\circ} \mathrm{C}$ for $24 \mathrm{~h}$. The samples were then centrifuged at $3,000 \mathrm{rpm}$, and aliquots of the supernate were obtained for the measurement of sodium, potassium, and urea. Upon completion of these studies, the samples were placed in an oven maintained at $\cong 100^{\circ} \mathrm{C}$ and allowed to dry to a constant weight. The solute content of the tissue was determined with the following formula: ${ }^{x}$ tissue $=\left({ }^{\mathrm{T}} \mathrm{H}_{2} \mathrm{O}+{ }^{\mathrm{D}} \mathrm{H}_{2} \mathrm{O} /{ }^{\mathrm{T}} \mathrm{H}_{2} \mathrm{O}\right) \cdot{ }^{\mathrm{x}} \mathrm{Obs}$, where $\mathrm{X}$ is the concentration of the variable (sodium, potassium, or urea). ${ }^{\mathrm{T}} \mathrm{H}_{2} \mathrm{O}$ represents the tissue water, ${ }^{D} \mathrm{H}_{2} \mathrm{O}$, the weight of the added water, and ${ }^{x} \mathrm{Obs}$, the measured concentration of the variable in the supernate. Tissue osmolality was calculated according to the following formula: $\mathrm{Osm}=1.84$ $(\mathrm{Na}+\mathrm{K})+$ urea

The concentration of inulin in plasma and urine was determined by the anthrone method (21). Plasma and urinary sodium and potassium concentrations were estimated with standard flame photometry (Instrumentation Laboratory, Inc., Lexington, Mass.). The osmolality was measured with a vapor pressure osmometer (Wescor, Inc., Logan, Utah). Blood urea nitrogen was determined by an enzymatic method (22).

Mean differences in whole kidney and superficial nephron function were tested for significance with the Student's $t$ test for unpaired data when comparing two groups of animals and for paired data when comparing measurements obtained in the same animal (23). 
TABLE I

Body Weights, Blood Pressures, and Plasma Parameters in Control and UUO Rats*

\begin{tabular}{lccccccc}
\hline & $\begin{array}{c}\text { Body } \\
\text { weight }\end{array}$ & $\begin{array}{c}\text { Blood } \\
\text { pressure }\end{array}$ & Hematocrit & $\mathrm{Na}$ & $\mathrm{K}$ & Osmolality & $\begin{array}{c}\text { Blood urea } \\
\text { nitrogen }\end{array}$ \\
\hline & $\mathrm{g}$ & $m m \mathrm{Hg}$ & $m l / 100 \mathrm{ml}$ & meq/liter & meq/liter & mosmol/kg & $\mathrm{mg} / 100 \mathrm{ml}$ \\
Control, $n=13$ & $48.6 \pm 3.3$ & $108 \pm 5$ & $39.5 \pm 0.9$ & $149 \pm 1$ & $4.6 \pm 0.2$ & $290 \pm 3$ & $18.7 \pm 2.4$ \\
UUO, $n=14$ & $42.8 \pm 0.9$ & $99.4 \pm 1.5$ & $39.2 \pm 1.3$ & $141 \pm 1$ & $4.6 \pm 0.2$ & $293 \pm 3$ & $22.0 \pm 2.0$ \\
\hline
\end{tabular}

* Values are the mean \pm SEM. $n$, number of rats studied in each group.

\section{RESULTS}

Table I shows the mean values for body weight, blood pressure, and plasma parameters measured in 13 control and 14 UUO rats which were studied with micropuncture techniques. No significant differences in these measurements were observed between the two groups. The mean weight of the micropunctured kidney was $333 \pm 17 \mathrm{mg}$ (SEM) in the UUO group vs. $286 \pm 15 \mathrm{mg}$ for the contralateral untouched kidney $(P<0.001)$. This reflected a mean difference of 17.1 $\pm 3.1 \%$. The weight of the left kidney in the UUO group was also significantly greater than that of the control group $(290 \pm 13 \mathrm{mg}, P<0.05)$. The mean difference between the right and left kidney of the control group was $5.9 \pm 2.3 \%$, the right kidney being slightly greater in weight than the left kidney. This slight but significant difference in kidney weights probably reflects a more careful removal of the perirenal fat tissue, dissection of the renal pedicle, and removal of the ureter from the left kidney.

As in previous studies $(4,9,12)$, the appearance of surface nephrons after release of unilateral ureteral blockade was markedly different from that of control animals. The lumen of most tubules were markedly narrowed and many were collapsed. As in the studies of Jaenike (12), tubule fluid collections from superficial nephrons was difficult. Because of the extremely low flow-rates in these tubules, it was nearly impossible to obtain fluid near the end of the proximal tubule as judged by its proximity to the central arteriole. It is because of this that surface nephrons in both groups were randomly punctured with a tendency to avoid sites near the end of the proximal tubule in both the UUO and control groups.

There were few differences in the appearance of the papilla after relief of UUO when compared with the controls. The mean length of papilla exposed and available for micropuncture in the UUO group averaged $0.88 \pm 0.11 \mathrm{~mm}$ (range $0.6-1.9 \mathrm{~mm}$ ) and was not different from that of controls (mean $1.16 \pm 0.09 \mathrm{~mm}$, range 0.97-1.57 mm). This is in marked contrast to the appearance of the renal papilla after relief of BUO where only $0.4-0.6 \mathrm{~mm}$ of papilla was available to micropuncture (8).

\section{Whole kidney function}

The results of renal clearance studies performed in 12 rats after relief of either right or left ureteral obstruction are depicted in Figs. 1-3. Glomerular filtration rate (GFR) after relief of UUO was strikingly reduced when compared with the contralateral control kidney $(P<0.001)$. However, these changes were independent of whether the kidney was placed in a glass cup and bathed with mineral oil (left ureteral obstruction) or whether the kidney remained untouched (right ureteral obstruction). Urine flow from the postreleased kidney was not significantly different than from the contralateral control kidney (CCK), nor
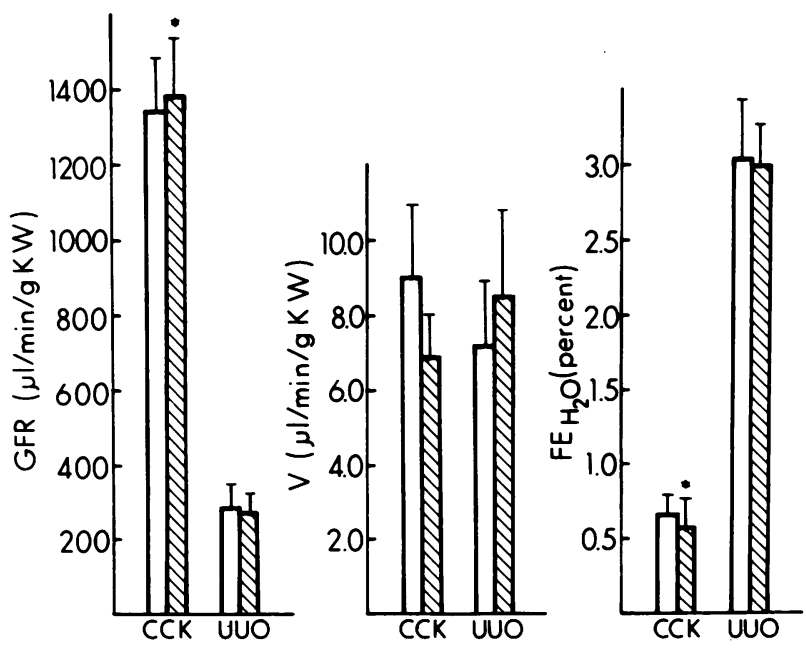

FIGURE 1 Renal function after release of UUO. Shown are the mean values and SEM for whole kidney GFR, urine flow (V) in microliters per minute per gram of $\mathrm{KW}$ and fractional excretion of water $\left(\mathrm{FE}_{\mathrm{H}_{2} \mathrm{O}}\right.$ ) for the postreleased (UUO) and the CCK. The clear bars represent the values obtained from the untouched kidney and the hatched bars represent the mean values obtained from kidneys prepared as if the micropuncture. Asterisks $\left({ }^{*}\right)$ indicate significant difference at $P<0.001$ from UUO independent of the degree of manipulation. 


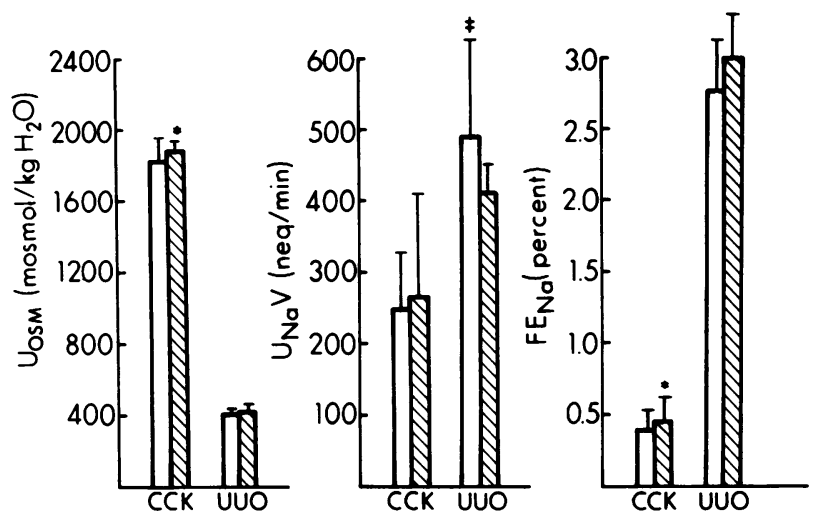

FIGURE 2 Renal function after release of UUO. Mean values for urine osmolality $\left(U_{0 s m}\right)$, absolute excretion of sodium $\left(\mathrm{U}_{\mathrm{Na}} \mathrm{V}\right)$, and fractional excretion of sodium $\left(\mathrm{FE}_{\mathrm{Na}}\right)$ are presented as described in Fig. 1 for the postreleased (UUO) and the CCK. Double dagger ( $\$$ ) indicates the level of significance for differences in absolute excretion of sodium when the unobstructed kidney is prepared as if for micropuncture was $P<0.01$. Asterisks $\left({ }^{*}\right)$ as in Fig. 1 .

was it significantly affected by being placed in the Lucite (E. I. DuPont deNemours \& Co., Inc., Wilmington, Del.) cup. As predicted, fractional excretion of water after release of obstruction (RUO $=3.07 \pm 0.75 \%$, LUO $=3.00 \pm 0.55 \%)$ was significantly greater $(P$ $<0.001$ ) than from the CCK. Sodium excretion was also significantly increased (Fig. 2). In absolute terms, Na excretion after release of RUO was significantly greater $(P<0.01)$ than from the CCK $(488 \pm 182$ vs. $254 \pm 160$ neq/min, respectively). After release of LUO, differences in sodium excretion were of a similar magnitude (412 \pm 139 in LUO and $250 \pm 76 \mathrm{neq} / \mathrm{min}$ in CCK) but did not achieve statistical significance. In both groups, fractional $\mathrm{Na}$ excretion was significantly higher after release of obstruction $(2.71 \pm 0.76 \%$ in RUO or $2.71 \pm 0.59 \%$ in LUO) when compared to the value of $<0.5 \%$ obtained in the CCK. Urine osmolality after relief of RUO or LUO was $\cong 400 \mathrm{mosmol} / \mathrm{kg}$, a value significantly lower than that of the CCK which exceeded $1,800 \mathrm{mosmol} / \mathrm{kg}$ in almost all cases.

In Fig. 3, changes of GFR after release of obstruction are plotted as a function of time. It is apparent that

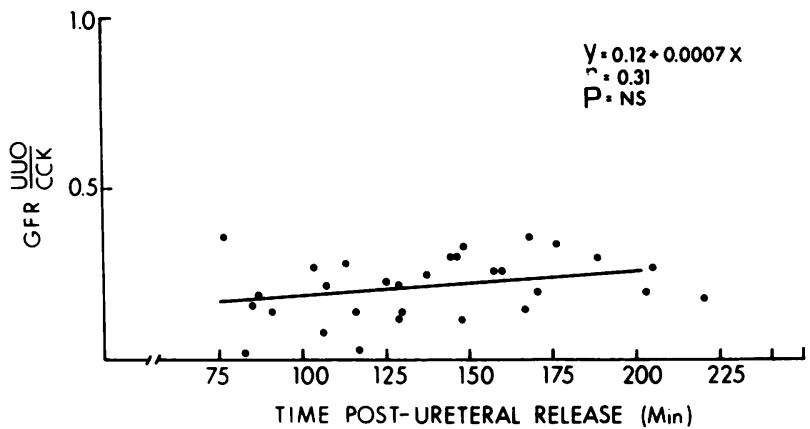

FIGURE 3 Whole kidney GFR plotted as a function of time after release of ureteral obstruction.

during the period in which the micropuncture studies were performed (60-180 min postrelease) there was no tendency for GFR to change $(r=0.31, P=\mathrm{NS})$.

\section{Micropuncture studies}

Tables II and III present data collected from the right untouched kidney in control rats and after release of UUO. Although urine flow tended to be slightly greater in the UUO group this did not achieve statistical significance. GFR, urine osmolality, and the absolute excretion of $\mathrm{Na}$ and $\mathrm{K}$ were not significantly different in the two groups.

The fractional excretion values for $\mathrm{Na}$ and water obtained from the contralateral nonmicropunctured kidneys are presented in Table III and compared to fluid collected near the tip of the papilla in the micropunctured kidney of control and UUO groups. In controls, the fraction of the filtered load of water excreted by the contralateral unmicropunctured kidney was $<1 \%$. However, a significantly greater amount of water remained near the tip of the papilla than was found in the final urine of the control kidney $(P<0.025)$. In the UUO group the fraction of filtered load of water excreted from the CCK was significantly greater than that of controls $(P<0.025)$. The fraction of the filtered load of water remaining at the tip of the papilla in this group averaged $3.40 \pm 0.66$ and reflected a nearly sixfold increase. This value is comparable to what was

TABLE II

Renal Function of the Right Untouched Kidney in Control Rats after Release of UUO

\begin{tabular}{|c|c|c|c|c|c|}
\hline & $\mathrm{V}^{*}$ & GFR & ${ }^{{ }^{N}} \mathrm{Na}^{v}$ & $\mathbf{u}^{\mathbf{v}}$ & UOsm \\
\hline & $\mu l / m i n / g K W$ & $\mu l / \min / g K W$ & neq/min & neq/min & mosmol/kg \\
\hline Control, $n=13$ & $5.59 \pm 0.61$ & $1189 \pm 121$ & $152.5 \pm 49.4$ & $371.4 \pm 42.9$ & $1636 \pm 68$ \\
\hline UUO, $n=14$ & $6.66 \pm 0.77$ & $948 \pm 72$ & $161.5 \pm 40.4$ & $277.2 \pm 39.4$ & $1628 \pm 46$ \\
\hline
\end{tabular}

\footnotetext{
* Values are the mean $\pm \mathrm{SEM} ; n$, number of rats studied in each group; $\mathrm{V}$, urine flow rate; ${ }^{\mathrm{U}} \mathrm{Na}^{\mathrm{v}}$, absolute rate of sodium excretion; ${ }^{\mathrm{U}} \mathrm{K}^{\mathrm{v}}$, absolute rate of potassium excretion; 'Osm, urine osmolality.
} 
TABLE III

Comparison of Renal Function of the CCK to Fluid Obtained from the Tip of the Collecting Ducts after Release of UUO of $18 \mathrm{~h}$ Duration and in Control Rats

\begin{tabular}{|c|c|c|c|c|c|c|c|c|c|}
\hline & \multicolumn{3}{|c|}{$\frac{P}{U} \operatorname{In} \times 100^{*}$} & \multicolumn{3}{|c|}{$\frac{\mathrm{U}}{\mathrm{P}} \cdot \frac{\mathrm{Na}}{\mathrm{In}} \times 100$} & \multicolumn{3}{|c|}{$\frac{\mathrm{U}}{\mathrm{P}}$ Osm } \\
\hline & CCK! & $\mathrm{CD}_{\mathrm{up}}$ & $P$ & CCK & $\mathrm{CD}_{\mathrm{tip}}$ & $P$ & CCK & $\mathrm{CD}_{\mathrm{Hp}}$ & $P$ \\
\hline $\begin{array}{r}\text { Control, } n= \\
\text { Mean } \pm \text { SE }\end{array}$ & $0.500 \pm 0.048$ & $0.751 \pm 0.102$ & $<0.025$ & $0.286 \pm 0.089$ & $0.625 \pm 0.138$ & $<0.025$ & $5.36 \pm 0.19$ & $4.60 \pm 0.26$ & $<0.05$ \\
\hline $\begin{array}{c}\text { UUO, } n=14 \\
\text { Mean } \pm \text { SE }\end{array}$ & $0.718 \pm 0.071$ & $3.40 \pm 0.66$ & $<0.005$ & $0.451 \pm 0.117$ & $3.32 \pm 0.95$ & $<0.01$ & $5.35 \pm 0.17$ & $1.53 \pm 0.06$ & $<0.001$ \\
\hline$P$ & $<0.025$ & $<0.001$ & & NS & $<0.01$ & & NS & $<0.001$ & \\
\hline
\end{tabular}

* $\frac{P}{U}$ In $\times 100$, percent of filtered load of water remaining in the urine of the CCK and in fluid obtained from tip collecting duct sites $\left(C_{\mathrm{ttp}}\right)$ in the micropunctured kidney of control and UUO groups. $\frac{U}{P} \cdot \frac{N a}{I n} \times 100$ percent of filtered sodium remaining; $\frac{U}{P}$ Osm, ratio of osmolality of fluid obtained at these sites to that of plasma.

† Values are the mean $\pm \mathrm{SEM} ; n$, number of rats studied in each group.

found in the clearance studies presented in Fig. 2 and was significantly greater $(P<0.001)$ than that remaining at the tip collecting duct sites in the control group.

Similar changes were seen in the fractional excretion of sodium. Again, sodium excretion from the contralateral unmicropunctured kidney of the UUO group was slightly, although not significantly, greater than that of control. In both cases, the mean value was $<0.5 \%$. In controls, a significantly greater amount of sodium remained at collecting duct sites than in the final urine of the contralateral unmicropunctured kidney ( $P$ $<0.05$ ). After release of UUO, however, $3.32 \pm 0.95 \%$ of the filtered load of sodium remained. This reflected a sevenfold increase in the fraction of the filtered load of sodium excreted, and was significantly greater than the mean of sham-operated rats studied under identical conditions. Urine osmolality was similar in the two groups when the unmicropunctured kidneys were compared. However, there was a striking reduction in the osmolality of fluid collected near the tip of the papilla after release of $\mathrm{UUO}(\mathrm{TF} / \mathrm{P}$ Osm $=1.53$ \pm 0.06 ) when compared with fluid collected at similar sites in the control group ( $\mathrm{TF} / \mathrm{P} \mathrm{Osm}=4.6 \pm 0.26, P$ $<0.001)$.

\section{Nephron function}

Surface nephrons. After release of obstruction SNGFR of surface nephrons was significantly reduced, averaging $7.4 \pm 0.88 \mathrm{nl} / \mathrm{min}$ perg kidney wt $(\mathrm{KW})$ compared with control studies $(24.9 \pm 2.1 \mathrm{nl} / \mathrm{min}$ per $\mathrm{g}$ $\mathrm{KW}, P<0.001$, Table IV). This fall in SNGFR was associated with an even more striking decrease in tubular fluid flow rate. The mean value for tubular fluid flow rate was $3.2 \pm 0.34$ in the UUO group vs. $14.0 \pm 1.2$ $\mathrm{nl} / \mathrm{min}$ per $\mathrm{g} \mathrm{KW}$ in the control group. This low tubular fluid flow rate made collections from surface nephrons after release of UUO extremely difficult, and frequently such collections had to be abandoned. The fraction of the filtered load of water reabsorbed to the site of micro-

TABLE IV

Nephron Function in Control Rats and after Release of UUO

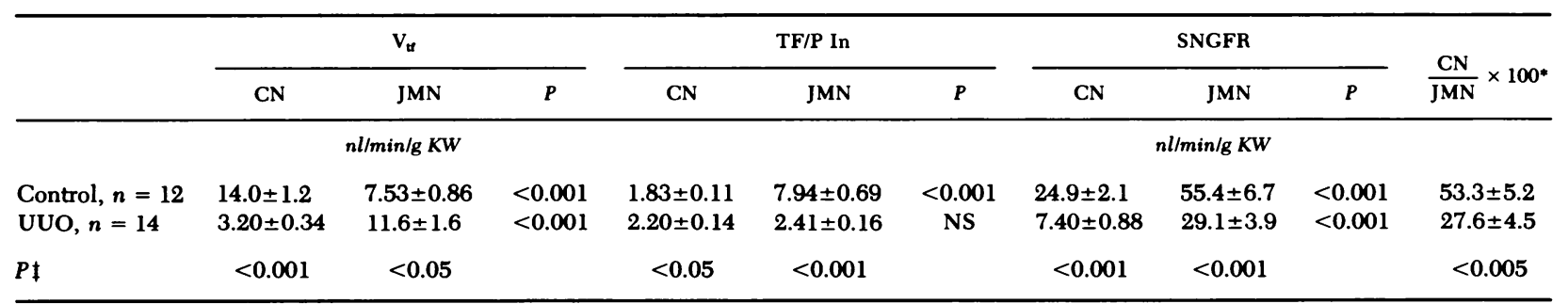

*Values are mean \pm SEM; $n$, number of rats studied in each group; cortical (CN) or juxtamedullary (JMN) nephrons; $\frac{\text { CN }}{J M N}$ SNGFR, ratio of mean SNGFR of cortical to juxtamedullary nephron.

† Level of significance for differences between control rats and UUO group. 
puncture was slightly, but significantly, greater in the UUO group compared to controls. This was reflected in a mean $\mathrm{TF} / \mathrm{P}$ In ratio of $2.20 \pm 0.14$ after release of $\mathrm{UUO}$ compared with $1.83 \pm 0.11$ in controls $(P<0.05)$.

JM nephrons. After release of obstruction, SNGFR of JM nephrons was significantly reduced, and averaged $29.1 \pm 3.9(P<0.001)$. As in controls, SNGFR of surface nephrons was significantly less than that of JM nephrons $(P<0.001)$. However, the decline in SNGFR after release of UUO was significantly greater in surface nephrons than in deep nephrons. Thus, the mean value for cortical SNGFR factored by that of deep nephron GFR averaged 27.6 $\pm 4.5 \%$ after release of UUO compared with $53.3 \pm 5.2 \%$

TABLE V

Micropuncture Data Obtained from Deep Nephrons 18 h after Release of UUO

\begin{tabular}{|c|c|c|c|c|c|c|c|c|c|c|}
\hline UUo & $v_{u}$ & TF/P In & SNGFR & Osm & $\mathrm{Na}$ & $\mathbf{K}$ & $\begin{array}{c}\text { Non- } \\
\text { electrolyte } \\
\text { solutes }\end{array}$ & $\frac{T F}{P}$. & $\frac{\mathrm{Na}}{\mathrm{In}} \times 100$ & $\frac{\mathrm{TF}}{\mathrm{P}} \cdot \frac{\mathrm{K}}{\mathrm{In}} \times 100$ \\
\hline & $n l / \min / g K W$ & & $n l / \min / g K W$ & mosmollkg & meqliter & meqliter & mosmollkg & & & \\
\hline 1 & $\begin{array}{l}2.39 \\
4.15\end{array}$ & $\begin{array}{l}3.54 \\
1.70\end{array}$ & $\begin{array}{l}8.45 \\
7.06\end{array}$ & $\overline{400}$ & $\begin{array}{l}150 \\
175\end{array}$ & $\begin{array}{l}4.4 \\
9.0\end{array}$ & $\overline{61.4}$ & & $\begin{array}{l}28.4 \\
69.1\end{array}$ & $\begin{array}{r}28.1 \\
123.6\end{array}$ \\
\hline 2 & $\begin{array}{l}9.84 \\
2.77 \\
8.75\end{array}$ & $\begin{array}{l}3.75 \\
2.67 \\
3.73\end{array}$ & $\begin{array}{c}36.9 \\
7.41 \\
32.6\end{array}$ & $\begin{array}{l}350 \\
515 \\
430\end{array}$ & $\begin{array}{l}182 \\
225 \\
220\end{array}$ & $\begin{array}{r}4.2 \\
10.2 \\
6.0\end{array}$ & $\begin{array}{l}6.67 \\
82.2 \\
14.2\end{array}$ & & $\begin{array}{l}34.0 \\
60.6 \\
43.4\end{array}$ & $\begin{array}{r}31.1 \\
101.3 \\
44.1\end{array}$ \\
\hline 3 & $\begin{array}{r}6.51 \\
19.88\end{array}$ & $\begin{array}{l}2.51 \\
2.37\end{array}$ & $\begin{array}{l}16.4 \\
42.2\end{array}$ & $\begin{array}{l}410 \\
360\end{array}$ & $\begin{array}{r}150 \\
-\end{array}$ & $\begin{array}{c}14.0 \\
-\end{array}$ & $\begin{array}{c}99.2 \\
-\end{array}$ & & $\begin{array}{c}41.5 \\
-\end{array}$ & $\begin{array}{c}136.6 \\
-\end{array}$ \\
\hline 4 & $\begin{array}{l}19.36 \\
14.95\end{array}$ & $\begin{array}{l}2.91 \\
4.62\end{array}$ & $\begin{array}{l}56.4 \\
69.1\end{array}$ & $\begin{array}{l}380 \\
390\end{array}$ & $\begin{array}{l}175 \\
140\end{array}$ & $\begin{array}{r}6.4 \\
10.0\end{array}$ & $\begin{array}{r}46.2 \\
114.0\end{array}$ & & $\begin{array}{l}42.8 \\
21.0\end{array}$ & $\begin{array}{l}66.5 \\
63.8\end{array}$ \\
\hline 5 & $\begin{array}{l}37.18 \\
21.84\end{array}$ & $\begin{array}{l}1.73 \\
1.74\end{array}$ & $\begin{array}{l}62.2 \\
38.0\end{array}$ & $\begin{array}{l}440 \\
425\end{array}$ & $\begin{array}{l}225 \\
210\end{array}$ & $\begin{array}{l}6.0 \\
6.0\end{array}$ & $\begin{array}{l}15.0 \\
27.6\end{array}$ & & $\begin{array}{l}84.7 \\
78.5\end{array}$ & $\begin{array}{l}82.7 \\
82.2\end{array}$ \\
\hline 6 & $\begin{array}{r}6.62 \\
16.62\end{array}$ & $\begin{array}{l}1.84 \\
1.65\end{array}$ & $\begin{array}{l}13.4 \\
27.5\end{array}$ & $\begin{array}{l}430 \\
440\end{array}$ & $\begin{array}{l}180 \\
235\end{array}$ & $\begin{array}{r}4.2 \\
12.0\end{array}$ & $\begin{array}{r}91.1 \\
-14.5\end{array}$ & & $\begin{array}{l}63.2 \\
91.0\end{array}$ & $\begin{array}{r}51.4 \\
162.0\end{array}$ \\
\hline 7 & $\begin{array}{l}11.52 \\
15.61\end{array}$ & $\begin{array}{l}2.83 \\
2.70\end{array}$ & $\begin{array}{l}35.9 \\
46.3\end{array}$ & $\begin{array}{l}440 \\
410\end{array}$ & $\begin{array}{l}150 \\
142\end{array}$ & $\begin{array}{l}5.50 \\
7.20\end{array}$ & $\begin{array}{l}153.9 \\
135.5\end{array}$ & & $\begin{array}{l}37.4 \\
37.2\end{array}$ & $\begin{array}{l}47.2 \\
67.5\end{array}$ \\
\hline 8 & $\begin{array}{l}8.42 \\
3.87\end{array}$ & $\begin{array}{l}2.55 \\
2.59\end{array}$ & $\begin{array}{l}21.5 \\
10.0\end{array}$ & $\begin{array}{l}395 \\
400\end{array}$ & $\begin{array}{l}162 \\
135\end{array}$ & $\begin{array}{l}7.0 \\
7.5\end{array}$ & $\begin{array}{r}84.0 \\
137.8\end{array}$ & & $\begin{array}{l}44.3 \\
36.6\end{array}$ & $\begin{array}{l}53.9 \\
52.0\end{array}$ \\
\hline 9 & $\begin{array}{l}10.81 \\
10.94\end{array}$ & $\begin{array}{l}2.27 \\
2.45\end{array}$ & $\begin{array}{l}24.5 \\
26.8\end{array}$ & $\overline{350}$ & $\begin{array}{l}150 \\
160\end{array}$ & $\begin{array}{l}4.4 \\
6.4\end{array}$ & $\overline{43.8}$ & & $\begin{array}{l}45.9 \\
45.7\end{array}$ & $\begin{array}{l}49.4 \\
61.3\end{array}$ \\
\hline 10 & $\begin{array}{r}13.50 \\
6.80\end{array}$ & $\begin{array}{l}1.80 \\
1.69\end{array}$ & $\begin{array}{l}24.3 \\
11.5\end{array}$ & $\begin{array}{l}290 \\
270\end{array}$ & $\begin{array}{l}145 \\
155\end{array}$ & $\begin{array}{l}6.0 \\
7.0\end{array}$ & $\begin{array}{r}12.2 \\
-28.1\end{array}$ & & $\begin{array}{l}56.1 \\
65.5\end{array}$ & $\begin{array}{l}53.1 \\
71.9\end{array}$ \\
\hline 11 & $\begin{array}{l}9.29 \\
8.61\end{array}$ & $\begin{array}{l}1.42 \\
1.44\end{array}$ & $\begin{array}{l}13.2 \\
12.4\end{array}$ & $\begin{array}{l}370 \\
385\end{array}$ & $\begin{array}{l}165 \\
150\end{array}$ & $\begin{array}{l}4.2 \\
4.0\end{array}$ & $\begin{array}{r}58.7 \\
102.0\end{array}$ & & $\begin{array}{l}79.9 \\
71.9\end{array}$ & $\begin{array}{l}84.5 \\
72.9\end{array}$ \\
\hline 12 & 25.70 & 2.64 & 67.9 & 400 & 150 & 6.4 & 112.0 & & 38.9 & 39.4 \\
\hline 13 & 7.47 & 2.10 & 15.7 & 410 & 157 & 6.0 & 110.0 & & 50.3 & 56.7 \\
\hline $\begin{array}{l}\text { Mean } \\
\pm \text { SE }\end{array}$ & $\begin{array}{r}11.72 \\
\pm 1.59\end{array}$ & $\begin{array}{r}2.41 \\
\pm 0.16\end{array}$ & $\begin{array}{r}28.0 \\
\pm 3.9\end{array}$ & $\begin{array}{r}395 \\
\pm 11\end{array}$ & $\begin{array}{r}168.7 \\
\pm 6.2\end{array}$ & $\begin{array}{r}7.1 \\
\pm 0.5\end{array}$ & $\begin{array}{r}66.6 \\
\pm 11.1\end{array}$ & & $\begin{array}{r}52.3 \\
\pm 4.0\end{array}$ & $\begin{array}{r}70.1 \\
\pm 6.7\end{array}$ \\
\hline $\begin{array}{l}\text { Control, } n \\
\quad \text { Mean } \\
\pm \text { SE }\end{array}$ & $\begin{array}{r}7.53 \\
\pm 0.86\end{array}$ & $\begin{array}{r}7.94 \\
\pm 0.69\end{array}$ & $\begin{array}{r}55.4 \\
\pm 6.7\end{array}$ & $\begin{array}{r}1,382 \\
\pm 67\end{array}$ & $\begin{array}{r}417.0 \\
\pm 28.0\end{array}$ & $\begin{array}{r}36.1 \\
\pm 5.5\end{array}$ & $\begin{array}{r}578.0 \\
\pm 72.0\end{array}$ & & $\begin{array}{r}40.7 \\
\pm 2.9\end{array}$ & $\begin{array}{r}106.8 \\
\pm 17.5\end{array}$ \\
\hline$P^{*}$ & $<0.05$ & $<0.001$ & $<0.001$ & $<0.001$ & $<0.001$ & $<0.001$ & $<0.001$ & & $<0.02$ & $<0.05$ \\
\hline
\end{tabular}

${ }^{*}$ Level of significance for differences between the UUO and control operated group; $\frac{\mathrm{TF}}{\mathrm{P}} \cdot \frac{\mathrm{Na}}{\mathrm{In}} \times 100$, fraction of filtered sodium remaining; $\frac{T F}{P} \cdot \frac{K}{I n} \times 100$, fraction of filtered potassium remaining at the site of micropuncture. 
TABLE VI

Percentage of Filtering Cortical and JM Nephrons before and 90 min after Release of UUO

\begin{tabular}{lccccccc}
\hline & \multicolumn{3}{c}{$\mathrm{CN}^{*}$} & & \multicolumn{3}{c}{ JMN } \\
\cline { 2 - 4 } \cline { 5 - 7 } & $\begin{array}{c}\text { No. } \\
\text { filtering }\end{array}$ & $\begin{array}{c}\text { No. } \\
\text { counted }\end{array}$ & Filtering & & $\begin{array}{c}\text { No. } \\
\text { filtering }\end{array}$ & $\begin{array}{c}\text { No. } \\
\text { counted }\end{array}$ & Filtering \\
\hline Before release, $n=5$ & & & $\%$ & & & & $\%$ \\
$\quad$ Obstructed kidney & 27 & 252 & $10.2 \pm 2.8$ & & 20 & 239 & $7.5 \pm 1.8$ \\
Contralateral kidney & 212 & 233 & $90.3 \pm 2.3$ & & 211 & 259 & $92.5 \pm 2.7$ \\
$P$ & & & $<0.001$ & & & & $<0.001$ \\
90 min after release, $n=5$ & & & & & & & \\
Postrelease kidney & 121 & 294 & $40.8 \pm 3.5$ & & 102 & 306 & $33.4 \pm 3.1$ \\
Contralateral kidney & 248 & 279 & $88.9 \pm 2.5$ & & 223 & 253 & $89.0 \pm 2.5$ \\
$P$ & & & $<0.001$ & & & $<0.001$ \\
\hline
\end{tabular}

${ }^{*} n$, number of rats studied in each group. $\mathrm{CN}$, cortical nephrons; JMN, juxtamedullary nephrons.

in the control group $(P<0.005)$. In contrast to controls, $\mathrm{V}_{\mathrm{t}}$ of deep nephrons in the UUO group was significantly greater than that of surface nephrons averaging $11.6 \pm 1.6 \mathrm{nl} / \mathrm{min}$ per $\mathrm{g} \mathrm{KW}$. Surprisingly, the mean $\mathrm{V}_{\mathrm{tf}}$ values of JM nephrons after release of UUO was also significantly greater than that obtained from deep nephrons in the control group $(P<0.05)$. The mean TF/P In ratio measured near the bend of the loop of Henle in the UUO group was significantly less than that of the control group $(2.41 \pm 0.16$ vs. $7.94 \pm 0.69$, respectively, $P<0.001$ ).

In Table $\mathrm{V}$, all the data obtained from JM nephrons after release of UUO and the mean values of 22 loop collections obtained from control rats are presented. The osmolality of fluid collected near the bend of the loop of Henle was significantly less $(P<0.001)$ after release of UUO than in control rats. This decline was related to a significant fall in sodium, potassium, and nonelectrolyte solutes. The fraction of filtered load of sodium remaining near the bend of the loop of Henle averaged $52.3 \pm 4.0 \%$ and was significantly greater than that of control studies $(40.7 \pm 2.9 \%, P<0.02)$. On the other hand, potassium remaining near the bend of the loop of Henle averaged $70.1 \pm 6.7 \%$ and was significantly less than the amount remaining at this site in controls $(106.8 \pm 17.5 \%, P<0.05)$.

\section{Ferrocyanide studies}

In these studies, the clearance measurements for the CCK and postreleased kidney were similar to values obtained and depicted in Figs. 1 and 2. The results of the microdissections presented in Table VI indicate that before release of UUO, the percent of filtering cortical and JM nephrons is sharply reduced $(10.2 \pm 2.8$ and $7.5 \pm 1.8 \%$, respectively) compared with CCK (90.3 \pm 2.3 , and $92.5 \pm 2.7 \%$, respectively, $P<0.001$ ). $90 \mathrm{~min}$ after release of UUO, the percentage of filtering neph- rons rose significantly in both populations, although to a slightly greater extent among cortical nephrons (40.8 \pm 3.5 vs. $33.4 \pm 3.1 \%$, in JM nephrons).

\section{IMPF studies}

In these studies, whole kidney function of the contralateral untouched kidney as judged by GFR, urine flow rate, sodium excretion, and urine osmolality at 90 and $180 \mathrm{~min}$ was not different from mean values obtained in micropuncture experiments and presented in Table II.

The IMPF yalues obtained at 0 time and 90 and $180 \mathrm{~min}$ after release of obstruction are graphically depicted in Fig. 4 and compared with control rats.

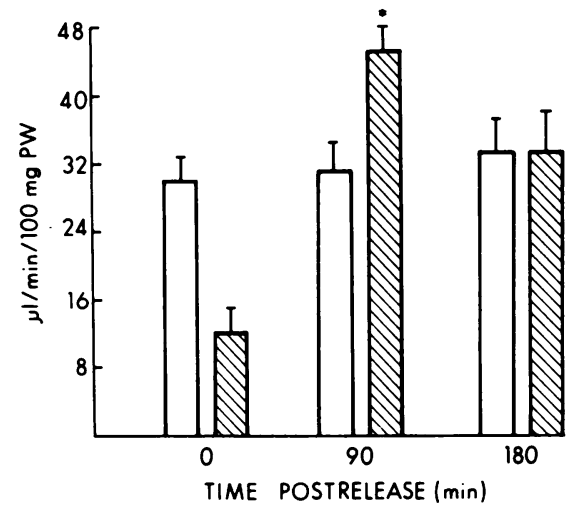

Figure 4 Effect of ureteral obstruction on IMPF. Values expressed per $100 \mathrm{mg}$ of papillary weight $(\mathrm{PW})$ were obtained in control rats (clear bars) and rats subjected to UUO (hatched bars) at a time before release (0) and 90 and $180 \mathrm{~min}$ after release of obstruction. The bars depict the mean and SEM of 11 cortical and $8 \mathrm{UUO}$ rats at zero time. At $90 \mathrm{~min}$, the mean of six rats in each group is presented. At the 180-min interval, IMPF measurements were obtained in six control and eight UUO rats. Asterisk $\left({ }^{*}\right)$ indicates significant differences at $P<0.001$ when compared to control values at $90 \mathrm{~min}$, or when compared to values obtained at zero time in the experimental group. 
IMPF averaged $29.8 \pm 3.1 \mu \mathrm{l} / \mathrm{min}$ per $100 \mathrm{mg}$ papillary wet weight in the control group before the papilla was exposed. $90 \mathrm{~min}$ after the ureteral pelvis had been removed, the mean IMPF value was $31.1 \pm 2.7 \mu \mathrm{l} / \mathrm{min}$ per $100 \mathrm{mg}$ papillary wet weight. The mean value obtained for the contralateral kidney was $24.0 \pm 1.7 \mu \mathrm{l} / \mathrm{min}$ per $100 \mathrm{mg}$ papillary wet weight, and reflected a difference of $29.9 \%$ which was statistically significant $(P<0.001)$. At $180 \mathrm{~min}$, the mean value for the left kidney was 33.2 $\pm 4.2 \mu \mathrm{l} / \mathrm{min}$ per $100 \mathrm{mg}$ papillary wet weight. This value was not significantly greater than the mean IMPF value obtained at 0 and $90 \mathrm{~min}$ after exposure of the papilla. As in the case of measurements obtained at 90 min, the mean IMPF value obtained for the contralateral kidney was less $(26 \pm 2.6 \mu \mathrm{l} / \mathrm{min}$ per $100 \mathrm{mg}$ papillary wet weight). Although measured IMPF values for the left kidney obtained at $180 \mathrm{~min}$ were always greater than those obtained for the right kidney, these differences did not achieve statistical significance.

Before release of UUO, IMPF was significantly reduced when compared with the control kidney and the contralateral kidney $(P<0.001)$. The mean value for the obstructed kidney was $12.1 \pm 1.7 \mu \mathrm{l} / \mathrm{min}$ per 100 mg papillary wet weight. There was a remarkable increase in IMPF at $90 \mathrm{~min}$ after ureteral release. The mean was $46.0 \pm 3.3 \mu \mathrm{l} / \mathrm{min}$ per $100 \mathrm{mg}$ papillary wet weight and exceeded control values as well as those obtained in the contralateral untouched kidney (mean difference $=61.1 \pm 10.8 \%$ ). By $180 \mathrm{~min}$, IMPF values after relief of UUO had returned to the normal range and averaged $33.2 \pm 5.2 \mu \mathrm{l} / \mathrm{min}$ per $100 \mathrm{mg}$ papillary wet weight.

\section{Tissue solute content}

In controls, the water content of the cortex and papilla was not significantly different, averaging 81.3 \pm 3.4 and $77.4 \pm 0.72 \%$, respectively. After release of UUO, the water content of cortical tissue was 81.8 $\pm 0.8 \%$ for the postreleased kidney. Papillary water averaged $89.5 \pm 1.9 \%$ of the total weight. The water content of both tissues exceeded control values but attained significance only with regard to the cortex $(P<0.001)$. Water content of the CCK in rats with UUO was not different from values obtained in controls.

Fig. 5 depicts the results obtained in the two groups of rats studied. In six control rats, the tissue osmolality of medulla was more than three times greater than that of the cortex and averaged 1,205 $\pm 106 \mathrm{mosmol} / \mathrm{kg}$ $(P<0.001)$. This was related to a marked rise in tissue urea and sodium. Potassium content of cortex and medulla was not different. In eight rats subjected to UUO, mean papillary osmolality averaged $428 \pm 23$ $\mathrm{mosmol} / \mathrm{kg}$. This value was slightly, but significantly, greater than that of the cortex $(346 \pm 14 \mathrm{mosmol} / \mathrm{kg}, P$ $<0.025)$. Values obtained from the contralateral
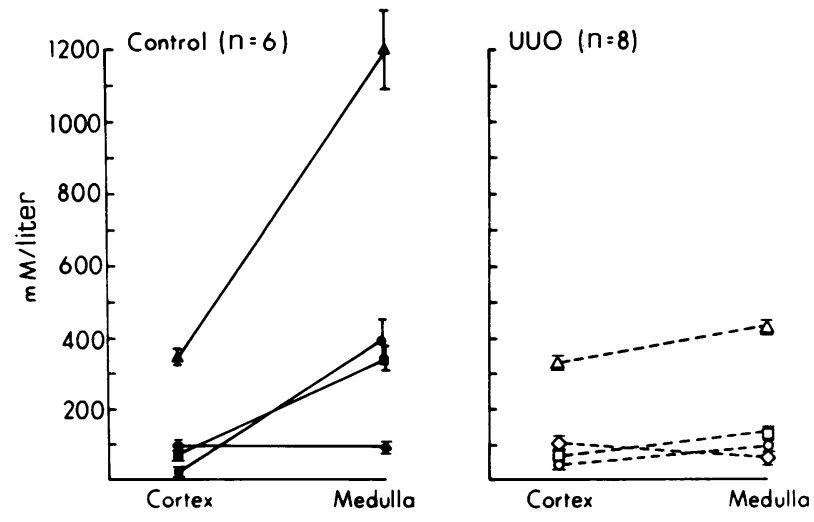

Figure 5 Tissue osmolalities and solute content of renal cortex and medulla in the two groups of rats studied. The concentration of urea $(\bullet)$, sodium $(\square)$, potassium $(\bullet)$, and the calculated osmolality $(\boldsymbol{\Delta})$ of cortex and medulla are graphically depicted for control rats and for rats subjected to UUO. $n$ is the number of rats in each study.

kidney of the UUO group were not different from the results obtained in the sham-operated groups.

\section{DISCUSSION}

Alterations in whole kidney function after release of UUO in the weanling rat (Figs. 1 and 2 ) are comparable to those seen in mature rats $(4,9,12)$, the dog $(13$, $14)$, and quite similar to the changes seen in man $(15,24,25)$. That is, GFR decreased fivefold when compared with the contralateral kidney, while urine flow and sodium excretion remained unchanged, thus reflecting a marked rise in fractional excretion of water and $\mathrm{Na}$. Furthermore, the capacity to form maximally concentrated urine was impaired. Similar to results obtained in adult rats $(4,9,12)$, cortical nephron function in the present studies was characterized by marked heterogeneity and increased fluid reabsorption along the proximal tubule. Fluid obtained from the tip of the exposed papilla after release of UUO was comparable in content to measurements obtained in the final urine in previous studies $(4,9)$. Fractional water and sodium content averaged over $3 \%$ of the filtered load, nearly fivefold greater than the water and sodium content of fluid collected near the tip of the papilla in hydropenic controls studied under identical conditions. The osmolality of tip collecting duct fluid after release of UUO was markedly depressed when compared with the osmolality of fluid obtained at a comparable site in the sham-operated group.

After release of UUO, superficial nephron GFR was reduced to $\cong 30 \%$ of controls. This decline was similar to our previous findings in weanling rats after release of BUO (8), and in more mature rats after release of either BUO or UUO (4). Furthermore, these findings are consistent with data previously reported by others 
(6, 7, 9). SNGFR of deep nephrons also fell significantly, averaging $\cong 29 \mathrm{nl} / \mathrm{min}$ per g KW. However, in contrast to the results obtained in cortical nephrons, the decline in deep nephron GFR was $<50 \%$ when compared with sham-operated rats. Furthermore, the ratio of cortical to deep nephron GFR was significantly less in the postreleased group (28\%) than after sham operation (53\%), which suggests that SNGFR is redistributed to JM nephrons. This decline in SNGFR of both populations of nephrons is significantly less $(30-50 \%$ controls) than that of total GFR (nearly fivefold). Because it is not possible to assess the number of functioning nephrons with micropuncture methodology, we used Hanssen's technique to estimate the percentage of filtering nephrons. We found that $90 \mathrm{~min}$ after relief of UUO, the percentage of filtering JM nephrons was $\cong 30 \%$, a value less than the $40 \%$ observed in cortical nephrons. This value of $30 \%$ for filtering JM nephrons, however, was somewhat greater than that found by Harris and Yarger (9). This discrepancy may be a result, in part, of the differences in the period of obstruction (18 vs. $24 \mathrm{~h}$ ), and the fact that in the present studies, careful attention was paid to fluid replacement, a factor known to effect changes in GFR after release of UUO (12). Thus, the differences seen between whole kidney GFR and SNGFR are a result, most likely, of cessation of filtration rate in a number of cortical and JM nephrons rather than to a selective loss of JM nephron function.

As in previous studies $(4,9)$ performed after relief of acute UUO, tubular flow in surface nephrons was markedly decreased (Table IV). This decline in the rate of flow made end proximal collections of tubular fluid nearly impossible. Therefore, we were not able to assess absolute or fractional water and $\mathrm{Na}$ reabsorption along this segment. Nevertheless, random collections indicated that fractional fluid reabsorption in this segment was $20 \%$ higher than in sham-operated rats, a finding consistent with previous observations $(4,9)$. If continued reabsorption of fluid occurs along the distal tubule of cortical nephrons, as has been shown in more mature rats (4), than these studies support the concept that increased fractional excretion of fluid and $\mathrm{Na}$ in the final urine is not a result of alterations in the handling of $\mathrm{Na}$ and water by cortical nephrons.

By contrast, mean values for tubular flow at the bend of the loop of Henle in deep nephrons exceeded control values by nearly $50 \%$ and the mean $\mathrm{TF} / \mathrm{P}$ In ratio at this site was significantly less than in controls. The decline in TF/P In ratios at the bend of the loop may be a result of a significant backleak of inulin. However, studies with microinjection techniques near the end of the proximal tubule reveal that inulin recoveries are not different from controls $14 \mathrm{~h}$ after relief of complete ureteral obstruction (5). These results suggest that the loop of surface nephrons and structures beyond are intact. Furthermore, Solez et al. (19) reported that papillary structures are morphologically intact after release of UUO. Most likely, the fall in the $\mathrm{TF} / \mathrm{P}$ In is a result of a decrease in fluid reabsorption to the site of micropuncture. The amount of water reabsorbed to the site of puncture in the UUO group averaged $16.7 \pm 2.8 \mathrm{nl} / \mathrm{min}$ per $\mathrm{g} \mathrm{KW}$ or $50.6 \pm 2.4 \%$ of the filtered load, a value significantly less than in control rats in both absolute $(44.9 \pm 5.2 \mathrm{nl} / \mathrm{min}$ per $\mathrm{g} \mathrm{KW}, P<0.001)$ and fractional terms $(85.9 \pm 0.90 \%, P<0.001)$. The site of altered tubular fluid reabsorption cannot be surmised unless the following assumptions are made: $(a)$ inulin is an adequate marker of GFR; $(b)$ the reabsorption of $\mathrm{Na}$ and water in the proximal tubules of deep nephrons is isosmotic; and (c) the reflection coefficient for $\mathrm{NaCl}$ in the descending limb of the loop of Henle (DLH) is $\cong 1$ and is not altered by obstruction (26). If allowed these assumptions, the fraction of the filtered $\mathrm{Na}$ load remaining at the bend of Henle's loop could be used to calculate the fraction of the filtered water remaining at the end of the proximal tubule of deep nephrons. In controls, nearly $41 \%$ of the filtered water remained at the end of the proximal tubule of JM nephrons (Table V), a value comparable to previous results obtained with these kinds of calculations $(8,27,28)$. By the bend of Henle's loop, $14.1 \pm 0.9 \%$ of the filtered water remained. Therefore, the amount of water reabsorbed along the DLH averaged $26.3 \pm 2.5 \%$ of the filtered load or $61 \pm 2.6 \%$ of the amount of water delivered to this segment. After release of UUO, $52 \%$ of the filtered water remained by the end of the proximal tubule of deep nephrons (Table V), significantly more $(P<0.02)$ by nearly $25 \%$ than the mean value in control rats. The fraction of the filtered load of water at the end of the DLH averaged $45.0 \pm 2.7 \%$. Therefore, $7.2 \pm 1.9 \%$ of the filtered water was reabsorbed along this segment of the nephron, and of the water load delivered to the DLH, only $12.2 \pm 3.0 \%$ was reabsorbed. These calculations suggest that the altered reabsorption of water to the bend of the loop of Henle after release of UUO is a consequence of decreased reabsorption of tubular fluid in the proximal segments of deep nephrons as well as in the movement of water out of the DLH.

The mechanisms responsible for decreased fluid reabsorption along the proximal tubule of JM nephrons after release of UUO are not completely clear. The decreased reabsorption may be a consequence of alterations in the physical factors that control fluid reabsorption. In the present studies, plasma flow to the inner medulla was sharply reduced before release of UUO, but $90 \mathrm{~min}$ post release exceeded those values obtained in sham-operated rats studied under identical conditions. The rise in IMPF seen at $90 \mathrm{~min}$ exceeded the increased values which are known to be the consequence of papillary exposure (29), and strongly suggest a greater blood flow to JM nephrons after release 
of UUO. The rise in IMPF occurred at a time when SNGFR of deep nephrons fell by nearly $50 \%$. Therefore the filtration fraction of JM nephrons was profoundly reduced. The fall in filtration fraction may underlie the decrease in fluid reabsorption along the proximal segment of JM nephrons.

The most marked changes in fluid reabsorption after release of UUO appeared to occur along the DLH. In the present studies, IMPF fell to roughly $40 \%$ of controls before release of UUO, while the percentage of filtering deep nephrons before release of UUO was $<8 \%$. Thus, relative to the filtration capabilities of JM nephrons, IMPF was increased. This relative increase in plasma flow to the inner medulla may dissipate the solute content of the papilla to the extent seen in the present studies (Fig. 5). Upon relief of obstruction ureteral, pressure falls (19) and flow through the vasa recta exceeds control values. The net effect may be a continued reduction in papillary osmolality and subsequent decline in the movement of water out of the DLH.

Whether the increase in the fractional and absolute delivery of water to the bend of DLH can account for the apparent reduction in net reabsorption of water beyond the end of the distal tubule of surface nephrons, reported previously (4), cannot be determined from the present studies, although an estimate of the absolute delivery of tubular fluid out of the DLH can be made if two assumptions are allowed: (a) that JM nephrons comprise $28 \%$ (30) of the 30,000 nephrons in the kidney $(31)$; $(b)$ that the mean value for SNGFR obtained in these studies is a fair representation for all filtering nephrons. Then delivery out of the DLH equals: SNGFR $\times \mathrm{FR}_{\mathrm{H}_{2} \mathrm{O}} \times \% \mathrm{~N}=28 \times 0.45 \times(0.33)$ $8,400=34.93 \mu \mathrm{l} / \mathrm{min}$, where $\% \mathrm{~N}$ is equal to the number of filtering nephrons and $\mathbf{F R}_{\mathrm{H}_{2} \mathrm{O}}$ is the fraction of the filtered water remaining at the bend of the loop of Henle. Delivery to the cortical collecting duct by superficial nephrons can be calculated in a similar manner if one assumes that the $\mathrm{FR}_{\mathrm{H}_{2} \mathrm{O}}$ remaining at the end of the distal tubule is $0.03 \%(4): 7.4 \times 0.03 \times(0.41)$ $21,600=1.97 \mu \mathrm{l} / \mathrm{min}$. Thus, even if significant reabsorption of sodium and water occurred in JM nephrons along the ascending limb of the loop of Henle and the distal tubule, delivery of fluid to the collecting duct by this population of nephrons in this experimental setting could significantly alter the composition of the final urine.

In conclusion, these studies demonstrate the pathophysiologic events which occur after release of UUO in weanling rats. The results suggest that deep nephron filtration rate is not as profoundly affected as cortical nephron GFR. That is, there appears to be a redistribution of SNGFR to JM nephrons after release of UUO. Furthermore, these studies indicate that in marked con- trast to superficial nephrons which demonstrate an increased fractional reabsorption of fluid, there is a marked reduction in the fractional reabsorption of water and sodium by deep nephrons, at least to the bend in the loop of Henle, and that this altered reabsorption appears to occur at two sites: the proximal tubule and the DLH. These observations are compatible with the postulate that changes in deep nephron function give rise to the net reduction of reabsorption in sodium and water between the end distal sites of cortical nephrons and the final urine. It is suggested that these differences in the renal tubular handling of sodium and water between surface and deep nephrons are a consequence of absolute and relative increases in blood flow to the medullary structures.

\section{ACKNOWLEDGMENTS}

We would like to express our appreciation to Susan Chambless for her excellent technical assistance, and Sandy Glenn for help in the final preparation of this manuscript.

These studies were supported by grants from the Veterans Administration (6930-02), the American Heart Association, Missouri Heart Affiliate, Inc. (42889), and the U. S. Public Health Service (AM 09976 and AM 07126).

\section{REFERENCES}

1. Winberg, J. 1959. Renal function in water-losing syndrome due to lower urinary tract obstruction before and after treatment. Acta Paediatr. 48: 149-163.

2. Roussak, N. J., and S. Oleesky. 1954. Water-losing nephritis. A syndrome simulating diabetes insipidus. Q. J. Med. 23: $147-164$.

3. Earley, L. E. 1956. Extreme polyuria in obstructive uropathy. Report of a case of "water-losing nephritis" in an infant, with a discussion of polyuria. N. Engl. J. Med. 255: 600-605.

4. Buerkert, J., E. Alexander, M. L. Purkerson, and S. Klahr. 1976. On the site of decreased fluid reabsorption after release of ureteral obstruction in the rat. J. Lab. Clin. Med. 87: 397-410.

5. McDougal, W. S., and F. S. Wright. 1972. Defect in proximal and distal sodium transport in post-obstructive diuresis. Kidney Int. 2: 304-317.

6. Yarger, W. E., H. S. Aynedjian, and N. Bank. 1972. A micropuncture study of postobstructive diuresis in the rat. J. Clin. Invest. 51: 625-637.

7. Jaenike, J. R. 1972. The renal functional defect of post-obstructive nephropathy. The effects of bilateral ureteral obstruction in the rat. J. Clin. Invest. 51: 2999-3006.

8. Buerkert, J., M. Head, and S. Klahr. 1977. Effects of acute bilateral ureteral obstruction on deep nephron and terminal collecting duct function in the young rat. J. Clin. Invest. 59: 1055-1065.

9. Harris, R. H., and W. E. Yarger. 1974. Renal function after release of unilateral ureteral obstruction in rats. Am. J. Physiol. 227: 806-815.

10. Harris, R. H., and W. E. Yarger. 1975. The pathogenesis of post-obstructive diuresis. The role of circulating natri- 
uretic and diuretic factors including urea. J. Clin. Invest. 56: $880-887$.

11. Wilson, D. R., and U. Honrath. 1976. Cross-circulation study of natriuretic factors in postobstructive diuresis. J. Clin. Invest. 57: 380-389.

12. Jaenike, J. R. 1970. The renal response to ureteral obstruction: A model for the study of factors which influence glomerular filtration pressure. J. Lab. Clin. Med. 76: 373-382.

13. Suki, W. N., A. G. Guthrie, M. Martinez-Maldonado, and G. Eknoyan. 1971. Effects of ureteral pressure elevation on renal hemodynamics and urine concentration. Am. J. Physiol. 220: 38-43.

14. Yarger, W. E., and L. D. Griffith. 1974. Intrarenal hemodynamics following chronic unilateral ureteral obstruction in the dog. Am. J. Physiol. 227: 816-826.

15. Gillenwater, J. Y., F. B. Westervelt, Jr., E. D. Vaughan, Jr., and S. S. Howards. 1975. Renal function after release of chronic unilateral hydronephrosis in man. Kidney Int. 7: $179-186$.

16. Vurek, G. G., and S. E. Pegram. 1966. Fluorometric method for the determination of nanogram quantities of inulin. Anal. Biochem. 16: 409-419.

17. Ramsay, J. A., and R. H. J. Brown. 1955. Simplified apparatus and procedure for freezing-point determinations upon small volumes of fluid. J. Sci. Instrum. 32: $372-375$.

18. Hanssen, O. E. 1958. A histochemical method for evaluation of excreted ferrocyanide in isolated tubules of the mouse kidney. Pathol. Microbiol. 44: 363-371.

19. Solez, K., S. Ponchak, R. A. Buono, N. Vernon, P. M. Finer, M. Miller, and R. H. Heptinstall. 1976. Inner medullary plasma flow in the kidney with ureteral obstruction. Am. J. Physiol. 231: 1315-1321.

20. Appelboom, J. W. T., W. A. Brodsky, W. S. Tuttle, and I. Diamond. 1957. The freezing point depression of mammalian tissues after sudden heating in boiling distilled water. J. Gen. Physiol. 41: 1153-1169.
21. Fuhr, J., J. Kaczamarczyk, and C-D. Kruttgen. 1955. Eine einfache colorimetrische Method zur Inulinbestimmung fur Nieren-clearance-Unterschungen bei Stoffwechselgesunden und Diabetikern. Klin. Wochenschr. 33: 729-730.

22. Fawcett, J. K., and J. E. Scott. 1960. A rapid and precise method for the determination of urea. J. Clin. Pathol. (Lond.). 13: 156-159.

23. Snedecor, G. W., and W. G. Cochran. 1967. Statistical Methods. Iowa State University Press, Ames, Iowa. 6th edition. 91-119.

24. Better, O. S., S. Tuma, S. Kedar, and C. Chaimowitz. 1975. Enhanced tubular reabsorption of phosphate. Arch. Intern. Med. 135: 245-248.

25. Better, O. S., A. I. Arieff, S. G. Massry, C. R. Kleeman, and M. H. Maxwell. 1973. Studies on renal function after relief of complete unilateral ureteral obstruction of three months' duration in man. Am. J. Med. 54: 234-240.

26. Kokko, J. P. 1970. Sodium chloride and water transport in the descending limb of Henle. J. Clin. Invest. 49: 1838-1845.

27. Jamison, R. L., J. Buerkert, and F. Lacy. 1973. A micropuncture study of Henle's thin loop in Brattleboro rats. Am. J. Physiol. 224: 180-185.

28. Pennell, J. P., F. B. Lacy, and R. L. Jamison. 1974. An in vivo study of the concentrating process in the descending limb of Henle's loop. Kidney Int. 5: 337-347.

29. Chuang, E. L., J. J. Reineck, R. W. Osgood, R. T. Kunau, Jr., and J. H. Stein. 1978. Studies on the mechanism of reduced urinary osmolality after exposure of the renal papilla. J. Clin. Invest. 61: 633-639.

30. Sperber, I. 1944. Studies on the mammalian kidney. Zool. Bidrag. Från. Uppsala. 22: 249-431.

31. Dicker, S. E. 1970. Renal structure and ability to concentrate urine. In Mechanisms of Urine Concentration and Dilution in Mammals. The Williams \& Wilkins Company, Baltimore. 16-30. 